\title{
Didática, metodologia e Educação Física no Ensino Fundamental: Um diálogo epistemológico com as abordagens pedagógicas
}

\author{
Teaching, methodology and Physical Education in Fundamental Education: An epistemological
}

dialogue with pedagogical approaches

Enseñanza, metodología y Educación Física en Educación Fundamental: Un diálogo epistemológico

con enfoques pedagógicos

Recebido: 24/06/2021 | Revisado: 01/07/2021 | Aceito: 02/07/2021 | Publicado: 15/07/2021

\author{
Silas Alberto Garcia \\ ORCID: https://orcid.org/0000-0001-9798-8219 \\ Universidade Federal de Goiás, Brasil \\ E-mail: silasgarcia11@gmail.com \\ Made Júnior Miranda \\ ORCID: https://orcid.org/0000-0002-5236-2367 \\ Universidade Estadual de Goiás, Brasil \\ E-mail: 118made118@gmail.com
}

\begin{abstract}
Resumo
O presente artigo tem por objetivo discutir e analisar, através de um diálogo epistemológico com algumas das principais abordagens pedagógicas da Educação Física, como a didática e a metodologia foram desenvolvidas nelas (nas abordagens pedagógicas) e após elas e quais são os objetivos da Educação Física no ensino fundamental nessas abordagens. Para isso, o texto foi estruturado em três seções. Em cada seção elegemos uma abordagem pedagógica da Educação Física para balizar o diálogo epistemológico. As abordagens analisadas são: a Desenvolvimentista, a Crítico-Superadora e da Educação de Corpo Inteiro. À guisa de conclusão, ponderamos que cada abordagem trouxe alguma contribuição ao campo, porém nenhuma é irreprochável, todas possuem falhas. Reconhecer isso teria sido muito mais profícuo e benéfico para o desenvolvimento da Educação Física do que a tendência de disputa ideológica pela conquista da hegemonia do campo.
\end{abstract}

Palavras-chave: Educação física; Epistemologia; Abordagens pedagógicas; Didática; Ensino fundamental.

\begin{abstract}
His article aims to discuss and analyze, through an epistemological dialogue with some of the main pedagogical approaches to Physical Education, how didactics and methodology were developed in them (in pedagogical approaches) and after them and what are the objectives of Physical Education in elementary education in these approaches. For this, the text was structured in three sections. In each section we choose a pedagogical approach to: Physical Education to guide the epistemological dialogue. The analyzed approaches are Developmental, CriticalOvercoming and Full Body Education. As a conclusion, we consider that each approach brought some contribution to the field, but none is irreproachable, all have flaws. Recognizing this would have been much more fruitful and beneficial for the development of Physical Education than the trend of ideological dispute for the conquest of the hegemony of the countryside.
\end{abstract}

Keywords: Pysical education; Epistemology; Pedagogical approaches; Didactics; Elementary school.

\begin{abstract}
Resumen
Este artículo tiene como objetivo discutir y analizar, a través de un diálogo epistemológico con algunos de los principales enfoques pedagógicos de la Educación Física, cómo se desarrolló la didáctica y la metodología en ellos (en los enfoques pedagógicos) y después de ellos y cuáles son los objetivos de la Educación Física en la educación primaria en estos enfoques. Para ello, el texto se estructuró en tres secciones. En cada sección elegimos un enfoque pedagógico de la Educación Física para orientar el diálogo epistemológico. Los enfoques analizados son: Educación del Desarrollo, Superación Crítica y de Cuerpo Completo. Como conclusión, consideramos que cada enfoque trajo algún aporte al campo, pero ninguno es irreprochable, todos tienen fallas. Reconocer esto hubiera sido mucho más fecundo y beneficioso para el desarrollo de la Educación Física que la corriente de la disputa ideológica por la conquista de la hegemonía del campo.
\end{abstract}

Palabras clave: Educación física; Epistemología; Enfoques pedagógicos; Didáctica; Enseñanza fundamental. 


\section{Introdução}

A década de 80 é conspecta como um marco para a história da Educação Física, uma vez que foi o período propulsor das discussões sobre a identidade da área (tendo a compreensão que na década de 70 já se havia um movimento incipiente que pairava no campo). Medina (1990), em seu clássico e preeminente livro A Educação Física cuida do corpo e... "Mente", colocou em pauta no cenário brasileiro a imprescindibilidade da Educação Física entrar em crise. Fazendo a leitura da conjuntura do processo de redemocratização do Brasil, o autor avistou que a crise fomentada pela busca de um novo cosmo que assolava quase todas as esferas sociais, não estava inquietando e encorajando o campo da Educação Física. Então, ela continuava em seu modus operandi realizando de forma subordinada e alienada as suas incumbências socialmente determinadas.

Na óptica de Medina (1990) o campo da Educação Física precisava imperiosamente de uma fundamentação mais crítica e de uma perspectiva mais humana. O foco das intervenções, sejam quais fossem os espaços de atuação, se centravam no adestramento do corpo, via de regra, a Educação Física se reduzia a um processo físico-biológico, não se tinha espaço para outras esferas da dimensão humana (intelectual, volitiva, emocional, social, etc.).

Ademais, a Educação Física não conseguia se legitimar em seus diversos espaços de intervenção, não possuía uma identidade bem definida e estava desassociada de suas finalidades mais significativas. Tal quadro era resultante do fato do processo de formação inicial dessa área ser demasiadamente defasado e, mormente, acrítico. Na análise de Medina (1990)

Isso se deve preponderantemente à falta de disposição crítica que tem caracterizado esse campo específico do conhecimento. Muito pouco se tem refletido - pelo menos de maneira séria e profunda - sobre o real significado de uma cultura do corpo que fundamente a Educação Física, propiciando, por parte de seus profissionais, uma atuação coletiva mais comprometida com um real estado de bem-estar físico, mental e social de toda a comunidade nacional, e não apenas da parcela privilegiada representante de uma minoria (Medina, 1990, p. 68).

Subsequente a essas provocações, outros autores - e atores da história da Educação Física - também passaram a defender a essencialidade de uma crise no campo. Tendo todo o cenário estruturado, a crise - que depois vieram a ser crises da Educação Física estava deflagrada. É neste contexto que o famigerado movimento Renovador da Educação Física ${ }^{1}$ é originado. Entres as discussões que pairavam no campo no período estava a preocupação com o ensino da Educação Física na escola. Desse debate, conforme Darido (2003), surgiram algumas proposições de abordagens pedagógicas que buscavam dar a Educação Física escolar uma nova forma para fazer contraposição às tendências tecnicista, esportivista e biologista.

A partir de então foram construídas tantas proposições de abordagens pedagógicas no campo que ulteriormente surgiram estudos que propositaram categorizá-las e classificá-las. Rezer, Nascimento \& Fensterseifer (2011), nos alerta para as possíveis limitações nestas propostas de classificações e categorizações das abordagens pedagógicas, pois é sempre tarefa complicada e arriscada tentar enquadrar e retratar certos "modos de pensar". Entretanto, elas nos permitem mapear as principais abordagens pedagógicas existentes, assim, podemos realizar a leitura e interpretação do contexto escolar com o auxílio deste(s) “mapa(s)”. Um destes “mapeamentos”, realizado por Darido (2003), nos apresentam as seguintes abordagens: Desenvolvimentista (Tani e Manoel); Construtivista-Interacionista (Freire); Crítico Superadora (Soares et al.); Sistêmica (Betti); Psicomotricidade (Le Bouch); Crítico-Emancipatória (Kunz); Cultural (Daolio); Jogos Cooperativos (Brotto); Saúde Renovada (Guedes \& Guedes e Nahas); Parâmetros Curriculares Nacionais $\neg-$ PCNs - (Jabu e Costa).

${ }^{1}$ Para Machado e Bracht (2016, p. 850), o movimento Renovador da Educação Física (MREF): pode ser entendido como um movimento de caráter "inflexor", dado ter representado um forte e inédito esforço de reordenação dos pressupostos orientadores da Educação Física, como, por exemplo, "colocar em xeque", de maneira mais intensa e sistemática, os paradigmas da aptidão física e esportiva que sustentavam a prática pedagógica nos pátios das escolas. A despeito das diferenças internas ao próprio Movimento, pode-se dizer que, naquilo que concerne ao seu segmento crítico ou "revolucionário", destaca-se o fato de a Educação Física (EF) absorver e participar do debate sobre as teorias críticas da educação que se desenvolvia no campo mais geral da Educação no Brasil. Entre outras questões privilegiadas pelo MREF, estava a tentativa de garantir à EF Escolar o status de disciplina escolar - em contraposição à condição de "mera atividade"... 
Partindo de concepções, autores, teorias, filosofias e ideologias diversas, cada uma destas abordagens tentou dar à Educação Física escolar uma nova configuração. Esse talvez foi um dos poucos pontos de convergência. Um outro ponto seria que todas elas foram sistematizadas para fazerem oposição ao ensino tecnicista, biologicista e tradicional que prevalecia em nosso campo (Darido, 2003).

O surgimento das abordagens pedagógicas foi profícuo para o campo, tendo em vista que algumas limitações e déficits da Educação Física escolar daquele período foram solapadas, ao menos no campo teórico. A Educação Física escolar seguia em uma direção que necessitava urgentemente de uma transformação. É nesta conjuntura que as abordagens pedagógicas foram sendo gestadas. O ensino exacerbado da técnica, a reprodução do esporte na escola, a hegemonia dos conteúdos esportivos, a exclusão de alunos menos habilidosos, a lógica da aptidão física, o ensino acrítico, transmissivo e reprodutivo, a predominância do papel do professor etc., eram alguns dos problemas que os diferentes autores do movimento Renovador da Educação Física tiveram que enfrentar para a constituição de suas proposições.

As abordagens pedagógicas foram desenvolvidas buscando romper com essas problemáticas arroladas no parágrafo anterior e buscando dar a Educação Física uma configuração mais crítica e pedagógica. Outras questões que também estavam em jogo eram a identidade e a finalidade da Educação Física. Cada abordagem pedagógica buscou sustentar uma determinada identidade e objetivo para área. Nessa investigação nos interessa os elementos metodológicos, didáticos e as finalidades propostas para a Educação Física pelas abordagens pedagógicas.

Sendo assim, o presente artigo tem por objetivo discutir e analisar, através de um diálogo epistemológico com algumas das principais abordagens pedagógicas da Educação Física, como a didática e a metodologia foram desenvolvidas nelas (nas abordagens pedagógicas) e após elas e quais são os objetivos da Educação Física no ensino fundamental nessas abordagens.

Alguns estudos no campo da Educação Física (Darido, 2003; Palafox \& Nazari, 2007; Sanches Neto \& Betti, 2008; Rezer; Nascimento \& Fensterseifer, 2011) já se propuseram a analisar pormenorizadamente todas as principais abordagens pedagógicas. Levando isso em consideração e também o objetivo desse artigo, é pertinente ressalvar que serão analisadas (sem o objetivo de aprofundar) apenas alguns elementos das principais abordagens pedagógicas que avaliamos serem significativas para um diálogo epistemológico sobre didática, metodologia e finalidades da Educação Física no ensino fundamental. Para isso, o texto foi estruturado em três seções. Em cada seção elegemos uma abordagem pedagógica da Educação Física para balizar o diálogo epistemológico. As abordagens analisadas são: a Desenvolvimentista, a Crítico-Superadora e da Educação de Corpo Inteiro.

\section{Dialogando com a Abordagem Desenvolvimentista}

Considerando a grande visibilidade e popularidade que a abordagem Desenvolvimentista conquistou no campo da Educação Física (talvez pelas inúmeras críticas recebidas) e também o alvo de suas proposições, a Educação Física no ensino fundamental, avalio ser conveniente iniciar o diálogo epistemológico por ela. Para isso, apresentaremos sucintamente os principais elementos que constitui essa abordagem.

A abordagem Desenvolvimentista foi formulada através de bases epistemológicas e metodológicas advindas mormente da concepção do comportamento motor. Ela surge no final da década de 80 e é principalmente disseminada aqui no Brasil através da obra Educação física escolar: fundamentos de uma abordagem desenvolvimentista (Tani et al., 1988).

Os autores dessa abordagem concebem o movimento humano como objeto da Educação Física, sendo o objetivo desta, propiciar aos alunos a aprendizagem motora. Os desenvolvimentistas constroem sua abordagem na tentativa de elaborar uma proposta para a ação pedagógica do professor de Educação Física que possibilite trabalhar com crianças de quatro a quatorze anos de idade (estudantes do ensino fundamental) os conteúdos de modo que promova o aprendizado motor, levando 
em consideração a maturação cognitiva e fisiológica, o ambiente e o crescimento. Isso porque acreditam que há uma sucessão padrão nos processos de desenvolvimento, crescimento e aprendizagem motora. Assim, para eles, é preciso elaborar a aula pensando nestas características, pois há momentos mais propícios para o ensino de determinado conteúdo/conhecimento. Portanto, o princípio da abordagem desenvolvimentista consiste em compreender e ser capaz de trabalhar com a transformação dos processos de crescimento, desenvolvimento e aprendizagem (Tani et al., 1988; Tani, 2008).

Caracterizam o movimento como um "deslocamento do corpo num determinado padrão espacial e temporal e como um elemento observável e mensurável” (Tani et al., 1988, p. 8). Assim, compreendem o movimento apenas como uma ação biológica e fisiológica, sem considerar os fatores sociais e culturais que podem intervir na movimentação humana.

São caracterizados três domínios do comportamento humano, são eles: o domínio cognitivo, o domínio afetivo social e domínio motor. O domínio cognitivo está relacionado com os processos de processamento, armazenamento, gerenciamento e formação de informações. O domínio afetivo social é expresso através dos sentimentos, das emoções, da relação do indivíduo com o ambiente. Já o domínio motor representa os movimentos, as ações musculares, os gestos (Tani et al., 1988).

Apesar de haver esses três domínios, cada um contendo suas particularidades de atuação no corpo humano, os autores da abordagem desenvolvimentista defendem que o corpo humano funciona de forma sistêmica, pois o corpo humano trabalha por meio de um sistema aberto. Assim, os autores propõem dois princípios para explicar as ações humanas. O primeiro deles, é o princípio da totalidade, neste, compreende-se que em toda ação existe a participação de todos os domínios que agem de forma integrada. O segundo princípio, é o da especificidade, que consiste na concepção de que em certas ações/movimentos existe um enfoque maior em um determinado domínio, por exemplo, uma ação de gesto técnico do chute no futebol há o predomínio do domínio motor (Tani et al., 1988).

Tani et al. (1988) trabalham com a concepção de que o desenvolvimento motor é um processo sequencial e que depende do desenvolvimento cognitivo-fisiológico e do crescimento da criança. Assim, argumentam que existe uma ordem a ser seguida para que ocorra o desenvolvimento global da criança. Partem das ações mais simples às mais complexas, que eles caracterizam como habilidades básicas e habilidades específicas. Isso porque, a criança possui um certo padrão de aprendizado de acordo com seu desenvolvimento e é preciso respeitar esse padrão e trabalhar as habilidades em consonância com o desenvolvimento de cada criança. Assim, sustentar que os professores devem ajustar as atividades à criança e não a criança à atividade (TANI, 2008).

Conforme Tani et al. (1988) e Tani (2008) a perspectiva de habilidades básicas respalda-se na compreensão de que existem conhecimentos/habilidades elementares que são primordiais para o desenvolvimento da criança que sem elas as crianças não terão domínio das habilidades mais avançadas (específicas). Assim, compreendem os movimentos básicos como aqueles geneticamente estipulados. Nessa concepção os movimentos básicos seriam subdivididos em: habilidades locomotoras (andar, correr e saltar), habilidades de manipulação (arremessar, chutar, rebater e quicar). Já os movimentos específicos, avançados seriam aqueles advindos do meio externo.

Proferiram críticas ao fato de o ensino da Educação Física estar sendo focado na busca pelo produto e não pela valorização do processo, ou seja, valorizava-se muito o resultado, a técnica a performance, e esqueciam da parte da experiência, da construção, do desenvolvimento das atividades realizadas. "Os autores mostram preocupação com a valorização do processo de aquisição de habilidades, evitando-se o que denominam de imediatismo, e da busca do produto" (Darido, 2003, p. 5). Por fim, argumentam que o objetivo da abordagem Desenvolvimentista é elaborar uma proposta para contribuir no ensino da Educação Física para crianças através do aprendizado motor de forma que possibilite a formação global dos alunos (Tani et al., 1988).

Ponderamos ser necessário destacar alguns pontos cardeais para começar o diálogo epistemológico com a abordagem Desenvolvimentista: 1) a abordagem circunscreve a sua contribuição à dimensão do Comportamento Motor (desenvolvimento, 
aprendizagem e controle); 2) a finalidade da Educação Física para o ensino fundamental nesta abordagem se limita à aprendizagem motora, ao desenvolvimento motor e controle motor; 3) a abordagem focou nos fundamentos e não desenvolveu elementos didático-metodológicos e pedagógicos do processo de ensino-aprendizagem.

Como assinala Tani (2008) no período de desenvolvimento da abordagem Desenvolvimentista a Educação Física carecia de um teorizar crítico. Buscando contribuir com essa questão, a abordagem foi constituída a partir das bases da área do Comportamento Motor, tendo em vista que naquele período essa área era pouco explorada e conhecida no campo. Sendo assim, os fundamentos teóricos expostos e propostos pela abordagem Desenvolvimentista foram inovadores e contributivos no que concerne à esfera do comportamento motor.

Contudo, o comportamento motor é somente um dos diversos elementos que compõe a Educação Física. Os desenvolvimentistas focaram nos aspectos biofisiológicos (não deixando de ser aspectos inovadores) e com isso não exploraram e não desenvolveram as questões socioculturais. Se reportarmos às bases teóricas de Marx (2002) e Vigotski (1991, 2000, 2003), lembraremos que a dimensão sociocultural é fulcral para a constituição do ser humano, levando em conta que somos seres fundamentalmente sócio-históricos. Portanto, tendo isso por base, o ensino da Educação Física não deve se restringir aos elementos biofisiológicos, os elementos socioculturais são essenciais e precisam ser explorados.

Levando ao pé da letra, é totalmente inconsistente conduzir o ensino da Educação Física sem considerar os aspectos socioculturais. A Educação Física só é um dos componentes da Educação exatamente por possuir algum reconhecimento de significância social e cultural, o que a faz ser uma atividade humana (nos termos de Leontiev) de ordem sociocultural. A título de exemplificação, ensinar o Basquetebol (mesmo que apenas os elementos técnicos e táticos) para estudantes só faz sentido porque essa prática corporal possui determinados significados socioculturais, caso contrário, qual seria o sentido de ensinar alguém a ficar correndo atrás de uma bola para arremessá-la em uma cesta? Sem os seus elementos socioculturais a Educação Física não faria sentido e se fizesse se limitaria ao aprimoramento de nossos movimentos instintivos.

A finalidade da Educação Física no ensino fundamental para a abordagem Desenvolvimentista seria apenas contribuir para o desenvolvimento físico-motor dos escolares. De minha parte, embasado nas bases teóricas da Teoria Histórico Cultural e, sobretudo, de Zankov, avaliamos, a partir de uma reescrita epistemológica, que o propósito da Educação Física no Ensino Fundamental seria mais significativo se buscasse por meio da cultural corporal de movimento contribuir para o impulsionamento do desenvolvimento integral e para formação da personalidade dos estudantes. Por sua vez, na esteira de Zankov (1984), isso implicaria em um ensino que explorasse os planos do desenvolvimento cognitivo (intelectual), volitivo e emocional, não apenas a dimensão físico-motora.

Conforme a análise de Darido (2003, p. 5), a abordagem Desenvolvimentista sustenta como “. . . principal objetivo da Educação Física ... oferecer experiências de movimento adequadas ao . . nível de crescimento e desenvolvimento, a fim de que a aprendizagem das habilidades motoras seja alcançada". Essa concepção contribuiu demasiadamente para a propagação da “... questão da adequação dos conteúdos ao longo das faixas etárias. Como no domínio cognitivo, uma taxionomia para o desenvolvimento motor, ou seja, uma classificação hierárquica dos movimentos dos seres humanos, do nascimento à morte, deve ser estabelecida" (Darido, 2003, p. 5).

Essa concepção de desenvolvimento alvitrada pelos desenvolvimentistas remonta a uma tendência de que o desenvolvimento não depende do ensino, as crianças só conseguirão aprender aquilo que for compatível com a sua faixa de desenvolvimento, assim, o aprendizado está sujeito ao nível de desenvolvimento da criança, não podendo impulsioná-lo (crítica também cabível à abordagem da Psicomotricidade). Essa tendência foi solapada por Vigotski. Segundo Zankov (1984), ao investigar e discorrer sobre a relação entre ensino e desenvolvimento, Vigotski refutou as teorias que até então existiam sobre essa questão. Para ele nessa relação o ensino não deve se condicionar ao desenvolvimento, uma vez que o ensino não só 
pode se adiantar em relação ao desenvolvimento, como também pode impulsioná-lo. Desse modo, para Vigotski as crianças podem desenvolver aprendizados que superam o seu nível desenvolvimento.

Sendo assim, não se pode restringir o ensino em virtude do nível desenvolvimento da criança. Nesse contexto, o conceito da zona de desenvolvimento iminente é substancial. O ensino não deve focar apenas naquilo que as crianças já conseguem fazer ou que está em seu nível de desenvolvimento, o objetivo deve ser em oportunizar atividades que proporcione às crianças a possibilidade de avançar em relação ao seu nível de desenvolvimento atual (zona de desenvolvimento real). O ensino precisa ser desafiante para o estudante dado que

... onde o meio não cria os problemas correspondentes, não apresenta novas exigências, não motiva nem estimula com novos objetivos o desenvolvimento do intelecto, o pensamento ... não desenvolve todas as potencialidades que efetivamente contém, não atinge as formas superiores ou chega a elas com um extremo atraso (Vigotski, 2000, p $.171)$.

No que tange aos elementos didáticos e metodológicos, a abordagem Desenvolvimentista também deixou a desejar. Como a proposta da abordagem se circunscreveu apenas nos fundamentos (até porque esse era o foco principal da abordagem conforme Tani (2008), os elementos pedagógicos do processo de ensino-aprendizagem não foram desenvolvidos. A impressão que ficou é que o processo de ensino nessa abordagem seguiria na lógica da transmissão, na figura do professor como autoridade máxima, o que remete ao modelo tradicional de educação.

Os autores da abordagem Desenvolvimentista até refutaram a lógica dos professores conduzirem suas práticas pedagógicas apenas pela transmissão de sequências pedagógicas preestabelecidas. Para eles, os alunos também precisam aprender a saberem como, quando e onde utilizar adequadamente os movimentos e não apenas aprenderem a mecânica do movimento (Tani et al., 1988; Tani, 2008). Todavia, essa proposição não acompanhou uma perspectiva de superação da lógica de transmissão. Não há indicativos de que os estudantes deveriam ser levados a aprenderem autonomamente e criticamente a identificarem como, onde e quando utilizarem corretamente determinado movimento. Sendo assim, esses aprendizados só aconteceriam somente em decorrência da transmissão do professor, teria mais um caráter de memorização do que o desenvolvimento de um aprendizado crítico.

Além do mais, na abordagem Desenvolvimentista elementos caros para um ensino de qualidade, de acordo com Zankov (1984), como criatividade e autonomia não foram satisfatoriamente explorados. O ensino da Educação Física precisa potencializar a criatividade dos alunos, não basta apenas ensiná-los a executarem com primor técnico determinado gesto motor básico, é fundamental que eles sejam encorajados a pensar novas formas de se movimentar, de jogar, de recriar determinados movimentos, etc. Isso só será possível com a valorização da autonomia dos estudantes. Eles devem ser constantemente colocados para resolverem autonomamente (sem desconsiderar a cooperação dos colegas e do professor) desafios sobre os conteúdos trabalhados nas aulas, pois assim eles poderão aprender a serem criativos e autônomos e não mero reprodutores.

\section{Dialogando com a Abordagem Crítico-Superadora}

Prosseguindo com o diálogo epistemológico com algumas das principais abordagens pedagógicas da Educação Física irei subsequentemente apresentar sumamente, analisar e discutir alguns pontos centrais sobre a abordagem Crítico-Superadora. Mesmo que essa abordagem não tenha destinado as suas proposições especificamente para o ensino fundamental como a abordagem Desenvolvimentista, mas sim para toda a educação básica, alguns elementos propostos por ela são expressivos para estabelecermos algumas discussões.

O livro Metodologia do Ensino da Educação Física, escrito em 1992 por Carmen Lúcia Soares, Celi Taffarel, Elizabeth Varjal, Lino Castellani Filho, Micheli Escobar e Valter Bracht (daí a famigerada denominação de Coletivo de 
Autores) é o que dá origem à abordagem Crítico-Superadora. Neste livro os autores desenvolveram uma proposta de Educação Física embasada sobretudo no Materialismo Histórico Dialético, na pedagogia Crítico-Social de Libâneo e na pedagogia Histórico-Crítica de Demerval Saviani. A abordagem teve grande repercussão no campo da Educação Física e passou a ter “.. . representantes nas principais universidades do país e ... apresenta um grande número de publicações na área, especialmente em periódicos especializados" (Darido, 2003, p. 8).

A abordagem Crítico-Superadora toma como norte a luta de classe da sociedade capitalista para fundamentarem a sua proposição à Educação Física. Nesta concepção, a sociedade é dividida em classes, a classe dominante e a classe explorada. Cada classe busca alcançar seus interesses. Historicamente a classe dominante vem buscando manter e afirmar ainda mais seus privilégios e suas riquezas. Para conseguir isso, a classe dominante "desenvolve determinadas formas de consciência social (ideologia), que veicula seus interesses, seus valores, sua ética, e sua moral como universais ... " (Coletivo de Autores, 2012, p. 26).

Neste sentido, a proposta do Coletivo de Autores (2012) busca romper com esse paradigma social, almejando a hegemonia popular, diminuindo as desigualdades sociais e a exploração. Por isso essa pedagogia é denominada de críticosuperadora (busca-se superar e transformar a sociedade) e sua reflexão pedagógica possui alguns princípios elementares, estes são: diagnóstico, judicativo e teleológico. É diagnóstico porque se propõe a constatar, ler e interpretar os fatos da realidade. É judicativo por exprimir juízo através da ética que expressa os interesses de certa classe social. E é teleológico pelo fato de indicar uma orientação, uma meta de onde se quer chegar. A depender da classe social que traçar a orientação, ela poderá ser conservadora ou transformadora.

Nesta abordagem, a Educação Física passou a trilhar em rumos bem diferenciados. Os elementos socioculturais, econômicos, políticos recebem uma grande valorização - rompendo com a hegemonia dos aspectos biofisiológicos - e passam a ser o cerne das discussões do campo da Educação Física. A Educação Física é caracterizada como uma prática pedagógica que na escola possui como finalidade abordar e promover a crítica e reflexão sobre os conhecimentos e conteúdos da Cultura corporal (jogo, esporte, dança, ginástica, capoeira, etc.) que foram historicamente construídos e desenvolvidos pela humanidade.

Para os autores da abordagem Crítico-Superadora não é suficiente apenas ensinar os sobre determinados conteúdos, movimentos, técnicas e táticas (dimensões conceituais e procedimentais), é imprescindível a reflexão sobre a cultura corporal e que o currículo seja ampliado e dialético, estando condizente com os interesses das camadas populares, possibilitando-os que sejam capazes de constatar, interpretar, compreender e explicar a realidade social obscura e antagônica (Coletivo de Autores, 2012). Sobre isso, os autores argumentam:

A expectativa da Educação Física escolar, que tem como objeto a reflexão sobre a cultura corporal, contribui para a afirmação dos interesses de classe das camadas populares, na medida em que desenvolve uma reflexão pedagógica sobre valores como solidariedade substituindo individualismo, cooperação confrontando a disputa, distribuição em confronto com apropriação, sobretudo, enfatizando a liberdade de expressão dos movimentos - a emancipação -, negando a dominação e submissão do homem pelo homem (Coletivo de Autores, 2012, p. 41).

A Educação Física além dos seus elementos pedagógicos, passa a ser concebida pelo prisma político, pois partem da premissa que todo educador precisa ter definido o seu projeto político-pedagógico. Então, para essa abordagem, o professor de Educação Física deve ter bem definido qual o projeto de sociedade que o orienta, quais as reais necessidades e interesses de classe que ele assume, quais os princípios axiológicos que seleciona para serem estabelecidos por meio de sua prática e como relaciona a sua prática pedagógica com sua concepção de mundo (Coletivo de Autores, 2012).

Nesta lógica, os conteúdos da Educação Física devem surgir da realidade social dos estudantes da classe trabalhadora e permitir que consigam fazer uma leitura crítica da realidade, superando e transcendendo os determinantes que foram e são 
impostos a eles historicamente. Dessa forma, a tematização da cultura corporal necessita estar em consonância com os anseios da classe trabalhadora, para que assim sejam trilhados e arquitetados passos em direção da transformação e justiça social. Em síntese, isso significa constituir uma prática pedagógica que direcione e permita aos escolares aquilatar, problematizar, criticar e ressignificar no âmbito da sua realidade socioeconômica-política-cultural os conhecimentos/conteúdos da cultura corporal. Sobre a seleção dos conteúdos, o Coletivo de Autores (2012) assevera que:

A escola, na perspectiva de uma pedagogia crítica superadora . . ., deve fazer uma seleção dos conteúdos da Educação Física. Essa seleção e organização exige coerência com o objetivo de promover a leitura da realidade. Para que isso ocorra, devemos analisar a origem do conteúdo e conhecer o que determinou a necessidade de seu ensino. Outro aspecto a considerar na seleção de conteúdos é a realidade material da escola, uma vez que a apropriação do conhecimento da Educação Física supõe a adequação de instrumentos teóricos e práticos, sendo que algumas habilidades corporais exigem, ainda, materiais específicos (Coletivo de Autores; 2012, p. 63)

O Coletivo de Autores (2012) propõe também alguns princípios curriculares no trato com o conhecimento, estes são: a relevância social do conteúdo; contemporaneidade do conteúdo; adequação às possibilidades sociocognoscitivas do aluno; simultaneidade dos conteúdos enquanto dados da realidade; espiralidade da incorporação das referências do pensamento; provisoriedade do conhecimento. Neste sentido, o trato com o conhecimento é pautado numa concepção de totalidade, de movimento, mudança qualitativa e contradição, princípios estes de um currículo ampliado e dialético.

Em síntese depreende-se da proposição dos princípios curriculares que os conhecimentos e conteúdos devem ser selecionados e sistematizados cientificamente de forma a considerar a sua relevância e associação com a realidade dos estudantes; precisam ser o mais atual e burilado possível; o conteúdo tem de ser apropriado e acessível para a capacidade cognitiva do aluno e para a sua prática social; o ensino dos conteúdos deve acontecer de forma simultânea e integrada e não por etapas; os conhecimento devem ser tratados e incorporados de forma espiralada e não de modo linear; e a noção do conhecimento histórico que é mutável, não absoluto e incontestável, deve ser desenvolvida e explorada com os estudantes.

A partir disso e buscando superar o sistema de seriação, o Coletivo de Autores (2012), propõe o sistema de ciclos. Este é caracterizado por abordar os conteúdos de ensino de forma simultânea e espiralada. Conforme os autores

Nos ciclos, conteúdos são tratados simultaneamente, constituindo-se referências que vão se ampliando no pensamento do aluno de forma espiralada, desde o momento da constatação de um ou vários dados da realidade, até interpretá-los, compreendê-los e explica-los.

Dessa forma, os ciclos não se organizam por etapas. Os alunos podem lidar com diferentes Ciclos ao mesmo tempo, dependendo do(s) dado(s) que esteja(m) sendo tratado(s) (Coletivo de Autores; 2012, p. 36).

Existem diversos outros elementos que poderiam ser abordados da abordagem Crítico-Superadora, porém consideramos que os que foram explorados até aqui são suficientes para principiar algumas discussões epistemológicas.

Sendo a abordagem mais popular no campo da Educação Física, a abordagem Crítico-Superadora foi a que mais se aproximou dos fundamentos da Teoria Histórico-Cultural. O primeiro ponto - e talvez o mais crucial - de convergência consiste na fundamentação pelo Materialismo Histórico Dialético. Contudo, ainda que possuem a mesma base matricial epistêmica-filosófica, a abordagem Crítico-Superadora tomou rumos diferentes. Isso se deu especialmente porque ela se respaldou nos aspectos pedagógicos da pedagogia Histórico-Crítica, mas não se fundamentou com mais consistência nos aspectos psicopedagógicos da Teoria Histórico-Cultural.

Por conseguinte, a abordagem Crítico-Superadora focou nos elementos políticos-pedagógicos e ideológicos, almejando a transformação e justiça social. A abordagem avançou significativamente e proficuamente ao propor que a prática pedagógica em Educação Física seja conduzida de forma a oportunizar a reflexão sobre os elementos da cultura corporal para que os alunos sejam capazes de constatar, interpretar, compreender, explicar, ressignificar e transformar os 
conhecimentos/conteúdos apreendidos. Entretanto deixou, a desejar no que se refere ao processo de desenvolvimento integral e formação da personalidade dos escolares. Com o amparo da Teoria Histórico Cultural e das contribuições pedagógicas de Zankov compreendemos que o objetivo de qualquer ato educativo seja o de contribuir para o avanço do desenvolvimento integral e para a formação da personalidade dos escolares. Neste caso, com a Educação Física contribuindo para o desenvolvimento integral e para a formação da personalidade dos estudantes por meio dos conhecimentos da cultura corporal de movimento a reflexão crítica sobre estes conhecimentos aconteceria como consequência, afinal, estaria se formando um sujeito crítico, autônomo e emancipado.

Embora a abordagem Crítico-Superadora desenvolva alguns princípios didáticos contributivos como as proposições de princípios curriculares no trato com o conhecimento, ela não menciona e nem desenvolve nada em relação à teoria da zona de desenvolvimento iminente. Além dos conhecimentos/conteúdos terem que ser emergidos da realidade social dos alunos, é importante também saber o que os alunos já sabem, uma vez que como salientou Vigotski (1991) as crianças já entram na escola com algum aprendizado, assim, cabe a nós professores diagnosticar esse aprendizado, que representa a zona desenvolvimento real delas para conseguirmos explorar as suas zonas de desenvolvimento iminente. Outrossim, é imprescindível que nas aulas de Educação Física sejam sempre dados desafios e problemas para os alunos resolverem, pois assim a zona de desenvolvimento iminente deles estará sendo constantemente fomentada.

Em vista disso, se a abordagem Crítico-Superadora tivesse integrado o princípio da zona de desenvolvimento iminente na sua proposta de princípios curriculares, ela se tornaria ainda mais significativa e contributiva. No entanto, como ela se embasou mormente na pedagogia Histórica-Crítica e quase não recorreu aos fundamentos da Teoria Histórico-Cultural ficou essa lacuna nas suas proposições didático-metodológicas.

Uma outra limitação didático-metodológica da abordagem Crítico-Superadora (e talvez de todas as abordagens pedagógicas) consiste em ela ser uma proposição que surgiu do plano teórico, sem ter diálogo diretamente com os professores e com a realidade da Educação Física escolar. Apesar de esclarecerem no livro que as proposições seriam destinadas para auxiliar na prática pedagógica dos professores de Educação Física e que o objetivo seria de “. . . facilitar a reflexão e a prática pedagógica dos professores do magistério, do ensino médio e dos anos iniciais do ensino fundamental" (Coletivo de Autores, 2012, p. 28). Não foi bem isso que aconteceu na prática.

No posfácio da segunda edição do livro Metodologia do Ensino de Educação Física os autores da abordagem CríticoSuperadora foram convidados a fazerem uma releitura da obra após ela ter se tornado uma grande referência no campo da Educação Física. Valter Bracht, ao realizar sua releitura e análise sobre a obra, apresentou as principais críticas que a abordagem recebeu, dentre elas o autor destacou as que foram proferidas pelos professores. Ao versar sobre essas críticas, Bracht salienta que:

As críticas ou as observações críticas que eu tenho captado entre os professores são entre outras, as seguintes: o texto é muito complexo, é de difícil entendimento para universo e/ou arcabouço conceitual que os professores, que estão na prática dominam. . . . Acabou que a redação é sentida pelos professores da escola como um elemento dificultador para o entendimento. Tem se ouvido também a crítica de que o texto é muito teórico, ou seja, de que não dá indicações mais claras de como proceder por exemplo no item avaliação. Uma outra observação que a gente ouve é a de que trabalhar com a proposta exige um tempo para preparar material e também para estudar que os professores das escolas não têm (Coletivo de Autores; 2012, p. 147).

Ao expor seu ponto de vista sobre essas críticas, Valter Bracht reconhece que o livro deveria ter se atentado mais com a realidade e ao domínio conceitual dos professores da escola, considerando que as proposições da abordagem são designados a eles (Coletivo de Autores, 2012). 
Visto isso, percebe-se que a abordagem Crítico-Superadora não foi gestada a partir da realidade da Educação Física escolar e sim somente no plano teórico, faltou a relação direta com os problemas e dificuldades dos professores na escola. Além disso, a abordagem não se preocupou com o processo de formação dos professores, não oportunizou materiais, cursos que ajudasse os professores a trabalharem com essa abordagem na escola. O sistema Zankoviano nos evidencia e nos instrui que qualquer metodologia/abordagem de ensino será bem mais profícua se for desenvolvida estabelecendo nexos diretamente com a realidade educacional. Não basta apenas fazer proposições teóricas, é necessário intervir na realidade, é necessário preparar os professores para trabalhar com essa metodologia/abordagem, é preciso construir matérias didáticos, necessita-se oferecer e oportunizar palestras, seminários e cursos de formação (Zankov, 1984). Dessa forma os professores estarão mais habilitados e qualificados para atuar a partir das contribuições das metodologias/abordagens de ensino e assim conseguirão contribuir de forma mais concreta para a realidade educacional.

Outra questão da abordagem Crítico-Superadora que merece ser discutida não corresponde necessariamente às proposições feitas, mas sim com o modo que a maioria dos adeptos do universo acadêmico (docentes e discentes universitários) dessa abordagem passaram a utilizá-la. Em vez de analisarem as possibilidades e limitações, de buscarem aprimorar e burilar determinadas questões da abordagem Crítico-Superadora, começaram a usar a abordagem como se ela fosse infalível e a partir disso criaram uma querela com as demais abordagens do campo. Neste caso, como sublinha Tani (2008), buscaram afirmar hegemonicamente a abordagem Crítico-Superadora como a única capaz de contribuir para a Educação Física escolar. Ou seja, com isso perdeu-se o caráter de abordagem e passou a expressar uma diretriz. Portanto, dissipou-se o caráter crítico, deixando de fazer reflexões e atualizações sobre metodologia, ensino, didática, etc., se transformando em uma tendência diretiva e dogmática.

Seria muito mais significativo se os seguidores da abordagem Crítico-Superadora no lugar de apontar as falhas das outras abordagens e de querer se tornar hegemônica, incitando uma querela no campo, buscassem superar as limitações da sua abordagem a partir das contribuições de outras abordagens. Por exemplo, a abordagem deixou uma grande lacuna em relação aos aspectos biofisiológicos (especialmente em relação ao comportamento motor), pois eles praticamente não são desenvolvidos. Para superar essa lacuna e se tornar mais consistente e completa, poderiam utilizar as contribuições da abordagem Desenvolvimentista. Todavia, o que fizeram foi apontar os erros, falhas e limitações da demais abordagens como se a abordagem Crítico-Superadora fosse perfeita. Ledo engano!

\section{Dialogando com a Abordagem da Educação de Corpo Inteiro}

Uma outra abordagem pedagógica da Educação Física que vale apenas destacar alguns pontos dela para estabelecermos um diálogo epistemológico é a que foi desenvolvida por João Batista Freire no livro intitulado de Educação de corpo inteiro: teoria e prática da Educação Física publicado inicialmente em 1989. Essa proposta de Freire é conhecida como a abordagem Construtivista-Interacionista, porém levando em consideração que Freire não considera sua proposta construtivista, a denominaremos aqui de abordagem da Educação de Corpo Inteiro. Freire desenvolveu a sua abordagem principalmente a partir das bases teóricas de Piaget e Wallon. A justificativa para abordar essa abordagem pedagógica é que ela endereçou suas proposições especialmente para a educação infantil e ensino fundamental.

Freire (1991) começa desenvolvendo a sua abordagem proferindo críticas sobre o modo como a escola é organizada. Para ele, é totalmente prejudicial para o desenvolvimento e aprendizado das crianças a lógica de privá-las de se movimentarem e de brincarem. A educação não deve cercear a movimentação e o brincar das crianças, isso é algo característico do universo delas, logo, é fundamental que sejam ainda mais explorados na escola. Aludindo sobre o autor diz: 
Existe um rico e vasto mundo de cultura infantil repleto de movimentos, de jogos, de fantasia, quase sempre ignorado pelas instituições de ensino. Pelo menos até a $4^{\circ}$ série do primeiro grau, a escola conta com alunos cuja especialidade é brincar. É uma pena que esse enorme conhecimento não seja aproveitado como conteúdo escolar. Nem a Educação Física, enquanto disciplina do currículo, que deveria ser especialista em atividades lúdicas e em cultura infantil, leva isso em conta (Freire, 1991, p. 13).

Na concepção de Freire (1991), a escola ao ser organizar por meio da dicotomia corpo e mente acaba privilegiando o plano intelectual e relegando o plano corporal. Essa lógica leva ao paradigma de imobilidade corporal, o movimentar das crianças não tem importância, ao contrário, ele é visto como algo de indisciplina, quanto menos mobilidade mais a criança é vista como disciplinada. Para o autor, essa lógica precisa ser abandonada, pois uma educação só será concreta “. . . em conhecimento significativo, em formação para autonomia, em democracia ... " (Freire, 1991, p. 14) se corpo e mente forem compreendidos como elementos integrativos que compõem um único organismo. Então, é fundamental que o corpo também seja incluso como um componente fundamental na realidade das escolas.

Buscando superar algumas das limitações que a Educação Física possuía, Freire (1991) solapou a perspectiva de atribuir à Educação Física apenas o papel de contribuir para o processo de padronização de movimentos. Em sua intepretação, esse cânone não considerava fatores essenciais para o desenvolvimento das crianças como os afetivos, sociais e culturais. Isso não implica necessariamente que Freire preconiza que as crianças não devem possuir alguns gestos padrões em determinadas fases do desenvolvimento, que elas não precisam aprimorar seus movimentos, ele só não concorda em reduzir e limitar a função da Educação Física à apenas isso.

A proposta de Freire foi a primeira no campo da Educação Física a valorizar o papel formativo do brincar e do lúdico e também a reconhecer os conhecimentos já adquiridos pelas crianças em virtude desses fatores. Antes esses elementos tão caros para o aprendizado e desenvolvimento das crianças eram concebidos apenas como momentos de recreação, diversão, frivolidade, mas não se tinha a compreensão de que eles poderiam contribuir para impulsionar o aprendizado e desenvolvimento das crianças. A criança aprende e se desenvolve brincando e divertindo, por isso a imprescindibilidade de romper com a concepção da educação tradicional de que a escola não é lugar para brincar e para se divertir.

Neste viés, para Freire (1991) os conhecimentos advindos da cultura dos escolares presentes nas variadas brincadeiras e jogos deveriam também ser integrados e explorados na escola. Então, na abordagem da Educação de corpo inteiro a brincadeira e o jogo

. . . enquanto conteúdo/estratégia, tem papel privilegiado. É considerado o principal modo de ensinar, é um instrumento pedagógico, um meio de ensino, pois enquanto joga ou brinca a criança aprende. Sendo que este aprender deve ocorrer num ambiente lúdico e prazeroso para a criança (Darido, 2003, p. 8).

Ao entrar no debate sobre a forma como a Educação Física deveria ser orientada, Freire (1991) inova, e diz que a Educação Física não deve ser conduzida como sendo a educação do movimento, para o movimento e nem pelo movimento, na sua óptica, a Educação Física precisa ser compreendida como sendo a educação de corpo inteiro. Para o autor, até então a preocupação se centrava apenas com o movimentar, com o fazer, mas o não movimentar e o não fazer também são importantes para a educação das pessoas. Por isso a necessidade de uma educação do corpo inteiro, os escolares devem ser ensinados a se movimentarem e a fazerem, como também necessitam de serem ensinados a não se movimentarem e a não fazerem.

À abordagem de Educação do Corpo Inteiro pertence o mérito de ter sido a primeira e a única das principais abordagens pedagógicas da Educação Física a apresentar o conceito de Vigotski da zona de desenvolvimento iminente. Freire (1991) não explorou pormenorizadamente o conceito da zona de desenvolvimento iminente (talvez porque no período em que ele desenvolveu sua abordagem as teorias de Vigotski não eram muito conhecidas e divulgadas como as de Piaget), mas ele 
destacou a importância dela para os processos de ensino-aprendizagem e avaliação, o que já foi algo bem inovador e significativo

Tendo apresentando alguns aspectos principais da abordagem da Educação de Corpo Inteiro estamos em condições para realizarmos algumas análises.

A abordagem contribuiu demasiadamente com o campo ao trazer à tona a enorme importância do brincar e do lúdico para o processo de aprendizagem e desenvolvimento dos alunos. Deveras, é fundamental que as aulas de Educação Física no ensino infantil e nos anos iniciais do ensino fundamental valorize o universo lúdico das crianças (o brincar, a diversão, o movimentar etc.), oportunizando um ambiente de aprendizado acolhedor, alegre, divertido e motivante.

Embora a abordagem de Freire refute a perspectiva limitante da Educação Física focar somente no processo de padronização de movimentos, ela acaba caindo também em uma tendência similar a essa quando se orienta a partir das fases/períodos de desenvolvimento propostos por Piaget. Para esse autor o desenvolvimento depende sobretudo do processo evolutivo e maturacional e não possui relação com o processo de aprendizagem. Em vista disso, para Piaget o desenvolvimento acontece antes da aprendizagem e com isso as crianças ficam limitadas a aprender apenas aquilo que estiver em conformidade com seu período de desenvolvimento. Sabemos, a partir das contribuições de Vigotski que essa é uma concepção limitada, pois a aprendizagem não só influencia o desenvolvimento como pode fazer ele avançar (Souza Filho, 2008).

Então, mesmo que Freire (1991) tenha destacado a relevância da zona de desenvolvimento iminente, a sua fundamentação em Piaget, particularmente na teoria dos estágios de desenvolvimento, acaba restringindo e reduzindo todo o potencial dessa teoria criada por Vigotski. A zona de desenvolvimento iminente no caso da abordagem da Educação de Corpo Inteiro só poderia contribuir para aprendizados que estariam no período de desenvolvimento das crianças, ou seja, aprendizados já esperados e consequentemente não possibilitaria que o desenvolvimento delas fosse fomentado. As crianças ficariam estagnadas no nível/estágio de desenvolvimento delas, já que na teoria de Piaget o aprendizado não influi no desenvolvimento, por conseguinte, o conceito da zona de desenvolvimento iminente perderia a sua maior potencialidade de auxiliar no impulsionamento do desenvolvimento dos escolares. Destarte, o conceito de zona de desenvolvimento iminente na abordagem de Freire perde a sua consistência, coerência e também a sua principal contribuição para a educação.

Em conformidade com Darido (2003, p. 8), a abordagem da Educação de Corpo Inteiro “. . . tem o mérito de propor uma alternativa aos métodos diretivos, tão impregnados na prática da Educação Física. O aluno constrói o seu conhecimento a partir da interação com o meio, resolvendo problemas". Esse foi um avanço significativo para o campo da Educação Física. Contudo, como nenhuma abordagem é perfeita, faltou à abordagem de Freire abordar com mais exatidão os processos didáticometodológicos. O enfoque foi em como e o quê ensinar, porém praticamente não foi explorado o quando ensinar (como seria o sequenciamento do desenvolvimento dos conteúdos), como planejar e organizar o ensino, quais as estratégias para ensinar, o quê e como se aprende. Esses elementos didático-metodológicos são cruciais para a estruturação de um ensino qualificado.

Existem outras abordagens pedagógicas da Educação Física que poderiam ser retratadas, mas ponderamos que as três abordagens (Desenvolvimentista, Crítico-Superadora e Educação de Corpo Inteiro) que foram apresentadas e discutidas nos parágrafos anteriores já satisfazem as finalidades propositadas neste artigo.

\section{Considerações para Continuar Pensando}

É indiscutível que que as abordagens pedagógicas trouxeram várias e profícuas contribuições para o campo da Educação Física, principalmente para a constituição de uma dimensão teórica dos aspectos pedagógicos mais crítica e em contraposição aos paradigmas de esportivização, mecanicismo, biologização e transmissão e reprodução. No entanto, parece que após o surgimento das abordagens aconteceu um processo de alienação de alguns pesquisadores do campo que passaram a 
ser adeptos dogmáticos de determinada abordagem. Em consequência disso, engendrou-se no campo querelas entre os correligionários das abordagens.

Essa conjuntura de alienação e de querelas contribuiu para que determinadas limitações das abordagens permanecessem estagnadas e cristalizadas, pois no lugar de buscarem superar as lacunas de cada abordagem para aprimorá-las e burilá-las, se circunscreverem em apenas apontar os defeitos das demais abordagens. Cada abordagem trouxe alguma contribuição ao campo, porém nenhuma é irreprochável, todas possuem falhas. Reconhecer isso teria sido muito mais profícuo e benéfico para o desenvolvimento da nossa área do que a tendência de disputa ideológica pela conquista da hegemonia do campo.

Por sua vez, de nossa parte pressupomos que a consequência desse cenário de querela entre os adeptos das abordagens pedagógicas foi a criação de um cenário de contentamento acrítico com determinadas questões didático-metodológicas. As discussões sobre esses elementos ficaram estacionadas e restritas naquilo que as abordagens desenvolveram, poucos foram os avanços e aprofundamentos. Corrobora com isso o fato dos estudos de Caparroz e Bracht (2007), Betti et al. (2007) e Rezer (2015) chamarem a atenção para a necessidade de colocar a didática no centro das discussões da Educação Física. Para esses autores, ainda há muitas questões sobre a didática que precisam e carecem ser exploradas. Ratificamos a posição dos autores e acrescentamos que o mesmo se aplica para as questões metodológicas. No nosso entendimento os elementos didáticosmetodológicos necessitam estar em constante atualização e ressignificação.

Então, nesse artigo buscamos tecer algumas discussões e reflexões epistemológicas com as abordagens pedagógicas da Educação Física. A ideia basilar foi de estabelecer um diálogo epistemológico apresentando e abordando os pontos contributivos e algumas limitações de cada abordagem e não de defender e sustentar algumas delas como a melhor e mais apropriada para a Educação Física. É bem mais enriquecedor para o pensamento crítico e para o desenvolvimento da área mantermos uma postura que nos leve a compreender que nada é irreprochável e infalível, tudo está suscetível a possuir falhas. Nosso foco precisa se direcionar não só em aprendermos a analisar as possibilidades contributivas, mas também reconhecermos as limitações de cada teoria, abordagem, metodologia, etc. Desse modo, nos afastaremos de dogmas e, por conseguinte, manteremos nossa capacidade crítica.

\section{Referências}

Betti, M., Kunz, E., Araújo, L. C. G. de, \& Gomes-da-Silva, E. (2007). Por uma didática da possibilidade: implicações da fenomenologia de Merleau-Ponty para a educação física. Revista Brasileira de Ciências do Esporte, 28(2), 39-53.

Caparroz, F. E., \& Bracht, V. (2007). O tempo e o lugar de uma didática da educação física. Revista Brasileira de Ciências do Esporte, $28(2), 21-37$.

Coletivo de Autores. (2012). Metodologia do Ensino de Educação Física. (2a. ed.). Cortez.

Darido, S. (2003). Educação Física na escola: questões e reflexões. Ed. Guanabara Koogan.

FREIRE, João Batista. (1991). Educação de corpo inteiro: teoria e prática da Educação Física. (2a. ed.) Scipione.

Machado, T., \& Bracht, V. (2016). O impacto do movimento renovador da Educação Física nas identidades docentes: uma leitura a partir da "teoria do reconhecimento" de Axel Honneth. Movimento (ESEFID/UFRGS), 22(3), 849-860.

Marx, K., \& Engels F. (2002). A Ideologia Alemã. Martins Fontes.

Medina, J. P. S. (1990). A Educação Física cuida do corpo e ... "mente". (9a. Ed.), Paplrus.

Palafox, G. H. M., \& Nazari, J. (2007). Abordagens metodológicas do ensino da educação física escolar. Revista Digital, Buenos Aires, 12(112). https://www.efdeportes.com/efd112/abordagens-metodologicas-do-ensino-da-educacao-fisica-escolar.htm.

Rezer, R. (2015). Conhecimento, prática pedagógica e Educação Física: aproximações com o campo da didática... Movimento (ESEFID/UFRGS), 21(3), 803814.

Rezer, R., do Nascimento, J. V., \& Fensterseifer, P. E. (2011). Um diálogo com diferentes "formas-de-ser” da Educação Física contemporânea-duas teses (não) conclusivas... Pensar a prática, 14(2), 1-14. 
Research, Society and Development, v. 10, n. 8, e40710817521, 2021

(CC BY 4.0) | ISSN 2525-3409 | DOI: http://dx.doi.org/10.33448/rsd-v10i8.17521

Neto, L. S., \& Betti, M. (2008). Convergência e integração: uma proposta para a educação física de 5a. a 8a. série do ensino fundamental. Revista Brasileira de Educação Física e Esporte, 22(1), 5-23.

Souza Filho, M. L. de. (2008). Relações entre aprendizagem e desenvolvimento em Piaget e em Vygotsky: dicotomia ou compatibilidade? Revista Diálogo Educacional, 8(23), 265-275.

Tani, G. (2008). Abordagem desenvolvimentista: 20 anos depois. Journal of Physical Education, 19(3), 313-331.

Tani, G., et al. (1988). Educação física escolar: fundamentos de uma abordagem desenvolvimentista. EPU, Edusp.

Vigotski, L. S. (2000). A construção do pensamento e da linguagem. Martins Fontes.

Vigotski, L. S (1991). A formação social da mente. (4a. ed.). Martins Fontes.

Vigotski, L. S.(2003). Psicologia Pedagógica. Artmed.

ZANKOK, L. V. (1984). La ensenãnza y el desarrollo. Investigación pedagógica experimental. Editorial Progresso. 